\title{
Papers
}

\section{The characteristics and evolution of credit default swap trading}

\author{
Lei Meng and Owain ap Gwilym* \\ *Centre for Empirical Finance, School of Management and Business, Cledwyn Building, \\ University of Wales, Aberystwyth SY23 3DD UK. \\ Tel: + 441970 621834, Fax: + 441970 622409, E-mail: oma@aber.ac.uk
}

Received (in revised form): 21st May, 2007

Lei Meng is an assistant professor in finance at IESEG, Lille Catholic University, France. His research interests are focused on fixed income markets, particularly credit derivatives. He has published in the Journal of Fixed Income.

Owain ap Gwilym is Professor of Finance at the University of Wales, Aberystwyth. His research interests are in quantitative finance, including credit ratings and credit derivatives. He is a co-editor of Interactive Data's credit ratings publications. He has published widely, including in the Journal of Banking and Finance, Journal of Futures Markets, Financial Analysts Journal and Journal of Portfolio Management.

\section{Practical applications}

This paper analyses the characteristics of credit default swap (CDS) trading. The findings inform market participants of the existence of clustering in the terms of CDS contracts, and imply possible means for improved order execution by avoiding rarely used terms. The findings of seasonality in CDS trading activity are informative in relation to the timing of trades.

\section{Abstract}

This is the first systematic empirical study of the characteristics and the evolution of credit default swap (CDS) trading. We study single name reference entities and find a prevalence of five-year maturities, US\$5 million and US\$10 million notional amounts, senior-ranked underlying debt and modified restructuring clauses. We find increased trading up to 2003 and an increased ratio of trades to quotes in recent years. A decrease in daily volume since 2004 is likely to be caused by the recent increased use of CDS index-related products. The majority of reference entities have credit ratings from at least one international rating agency, and the average credit quality of the universe fluctuates during the sample period. Trading activity demonstrates an inverse $U$ shape across the week.

Journal of Derivatives \& Hedge Funds (2007) 13, 186-198. doi:10.1057/palgrave.jdhf.1850073

Keywords: credit default swaps; credit ratings; trading activity

\section{INTRODUCTION}

Credit derivatives allow users to manage credit risk by isolating credit risk from underlying financial assets. Although small relative to other derivative and security markets, the credit derivative market has become one of the fastestgrowing derivative markets since the late 1990s.
Journal of Derivatives \& Hedge Funds, Vol. 13 No. 3, 2007, pp. 186-198 (C) 2007 Palgrave Macmillan Ltd $1753-9641 \$ 30.00$ 
The British Bankers Association's (BBA) survey suggests that the global credit derivatives market increased in size (measured by notional amount outstanding) from around US $\$ 151$ billion in 1997 to US $\$ 514$ billion in $1999 .{ }^{1}$ Credit default swaps (CDS) account for a large share of the market. According to the BBA survey, ${ }^{1}$ around 50 per cent of the market was in CDS, while Patel $^{2}$ finds that CDS account for 72 per cent of the market. The International Swaps and Derivatives Association's (ISDA) market survey indicates that the outstanding notional amount of CDS was US $\$ 12.43$ trillion by the end of June 2005 . $^{3}$ Because of the market's rapid growth, CDS have attracted increasing attention in academic research. In recent years, there has also been an increase in CDS index trading, which has provided further depth to the market.

There have been a number of recent empirical studies on CDS that focus on recovery forms, pricing determinants, performance of pricing models ${ }^{4}$ and interaction between the CDS market and other markets. ${ }^{5}$ Commonly, only CDS premiums are used in these empirical studies, although some features of CDS such as maturity and notional amount may be considered in data filtering. Market information other than the actual prices of CDS transactions is largely ignored. However, information such as the rank of reference assets under CDS and the time when a quote is placed or a trade is closed, as well as time-varying features such as changes in volume can be valuable to the understanding of the characteristics of the CDS market and how it has been evolving. This paper aims to explore these previously under-researched aspects.

There are sporadic descriptions of CDS data in the literature. To the best of our knowledge, there is only one previous (nonacademic) empirical study by FitchRatings that systematically analyses the properties of CDS data. ${ }^{6}$ FitchRatings uses data obtained from GFI and Creditex, two leading brokers in the CDS market, to analyse (i) growth in the number of reference entities quoted (as an alternative measure of market growth ${ }^{7}$ ); (ii) trends in bidask spreads (as a proxy for liquidity) and the degree to which liquidity varies over time; and (iii) overall trends in trading efficiency (measured by the ratio of the number of bid prices to the number of offer prices). The time period of their sample is from January 2002 to September 2004.

Aunon-Nerin et al. ${ }^{8}$ use CDS data from an undisclosed broker. They describe (i) the industry distribution of reference entities; (ii) the top ten corporate and top ten sovereign reference entities between January 1998 and February 2000. Houweling and Vorst ${ }^{9}$ describe the distribution of currency, notional amount and maturity of CDS between May 1999 and January 2001. Their data are obtained from Creditex and CreditTrade (a broker), and from a number of commercial and investment banks. Ericsson et al. ${ }^{10}$ graphically depict the daily frequency of bid and offer quotes and the distribution of maturities of a CreditTrade CDS data set from January 1999 to December 2002. Hull et al. ${ }^{11}$ describe the maturity profile and report the annual number of bid and offer quotes, annual number of reference entities and the level of CDS premiums. They use data from GFI from January 1998 to May 2002. In summary, all the above literature reports the characteristics of CDS data before 2003.

This paper is the first systematic empirical study dedicated to analysis of the characteristics of CDS data. By analysing statistical features of the key factors that define a CDS transaction, we provide a distinctive insight into the practice of CDS trading. Further, the analysis of the 
time-varying features of CDS trading and evidence on the microstructure features will lead to a clearer understanding of the evolution of the CDS market. The findings may also provide supportive evidence to the increasing importance of CDS index trading.

The CDS data used in this paper are a sample of American market quoted prices (hereafter referred to as 'quotes') and traded prices (hereafter referred to as 'trades') from the Market Prices database of CreditTrade. ${ }^{12}$ CreditTrade divides Market Prices into America, Europe, Asia and Japan market prices. American market prices are defined as prices on reference entities from North America and Latin America. Therefore, the prices are not necessarily obtained from the US. The whole data sample used in this paper covers the period from 10th June, 1997 to 3rd March, 2005. The total number of reference entities in the data set is 945, including 72 banks, 846 corporates and 27 sovereigns. Risk Magazine reports that GFI, Creditex and CreditTrade were the most wellknown CDS data providers at that time. ${ }^{13}$ The CDS data service of CreditTrade covered 1,500 reference entities, and the coverage of Creditex and GFI's data services was 1,400 reference entities and 1,700 reference entities, respectively. This indicates that CreditTrade is among the leading participants in this CDS data services sector. Also, our data sample represents a substantial proportion of CreditTrade activity.

The remainder of this paper is organised as follows: The next section investigates the profile of the CDS market by examining the embedded features of CDS; the subsequent section analyses the availability of credit ratings for the reference entities quoted or traded in the market; the penultimate section explores trading activity and CDS indices and the final section concludes the paper.

\section{CDS MARKET PROFILE}

\section{Currency, rank and restructuring}

Table 1 presents results discussed here. The US dollar is the prevailing currency for American reference entities (North America and Latin

Table 1: Currency, rank, restructuring and credit type

\begin{tabular}{llr}
\hline & Frequency & Per cent \\
\hline Currency & & \\
USD & 375,760 & 99.867 \\
EUR & 478 & 0.1270 \\
JPY & 17 & 0.0045 \\
SGD $^{\text {a }}$ & 2 & 0.0005 \\
THB $^{\text {a }}$ & 2 & 0.0005 \\
XCD $^{\text {a }}$ & 1 & 0.0003 \\
& & \\
Rank & & \\
Senior & 369,927 & 98.32 \\
Subordinate & 5,556 & 1.48 \\
N/A & 777 & 0.21
\end{tabular}

Restructuring

$\mathrm{MR}^{\mathrm{b}}$

339,980

90.36

$\mathrm{OR}^{\mathrm{b}}$

25,739

6.84

$\mathrm{NR}^{\mathrm{b}}$

10,204

2.71

$\mathrm{MMR}^{\mathrm{b}}$

335

0.09

Credit type

Corporate

305,198

81.11

Sovereign

44,929

11.94

Bank

26,133

6.95

${ }^{\mathrm{a}} \mathrm{SGD}=$ Singapore dollar, $\mathrm{THB}=$ Thai Baht, $\mathrm{XCD}=$ East Caribbean Dollar.

${ }^{\mathrm{b}} \mathrm{MR}=$ modified restructuring; $\mathrm{OR}=$ old restructur -

ing; $\mathrm{NR}=$ no restructuring; $\mathrm{MMR}=$ modified modified restructuring. 
America), accounting for more than 99 per cent of all the CDS in our database. There are also a small proportion of CDS contracts denominated in euro (about 0.1 per cent). CDS denominated in other currencies, that is Japanese yen, Singapore dollar, Thai Baht and Caribbean dollar, are negligible. Aunon-Nerin et al. ${ }^{8}$ and Houweling and Vorst ${ }^{9}$ also report US $\$$ as the most frequently quoted currency.

In the whole sample, 98.3 per cent of reference debt is senior-ranked, while only 1.5 per cent is subordinated debt ${ }^{14}$ (see Table 1). This phenomenon may be due to several factors. First, subordination involves analysis of sensitivity of the default to the value of the debt, which makes the pricing of CDS more complex. ${ }^{15}$ Secondly, FitchRatings suggests that structured finance securities usually involve a list of 'soft' credit events, ${ }^{16}$ and ISDA is still developing standardised structured finance documentation.

Table 1 also shows the use of restructuring clauses in CDS quotes. The prevailing use of modified restructuring (MR) in the American entities' market is consistent with FitchRatings' finding. MR is used in the majority of cases, followed by Old Restructuring (OR), which accounts for 6.8 per cent in the whole sample. ${ }^{17}$

Table 1 also identifies the distribution of credit type. More than 80 per cent of the trades and quotes are on corporate reference entities. Sovereign entities and bank entities account for approximately $2 / 3$ and $1 / 3$ of the rest, respectively. US reference entities are dominant, with 87.2 per cent in the whole sample. Four Latin American sovereigns, that is Brazil, Mexico, Columbia and Venezuela are heavily represented. They account for 85.2 per cent $(38,266$ of 44,929$)$ of sovereign quotes and trades, and 10.2 per cent $(38,266$ of 376,260$)$ of the whole sample.

\section{Notional amount}

Figure 1 shows the distribution of the most frequently used 12 notional amounts, which account for more than 99 per cent of all the quotes and trades. ${ }^{18}$ Notably, the most popular five notional amounts, that is, $\$ 5$ million, $\$ 10$ million, $\$ 2$ million, $\$ 3$ million and $\$ 20$

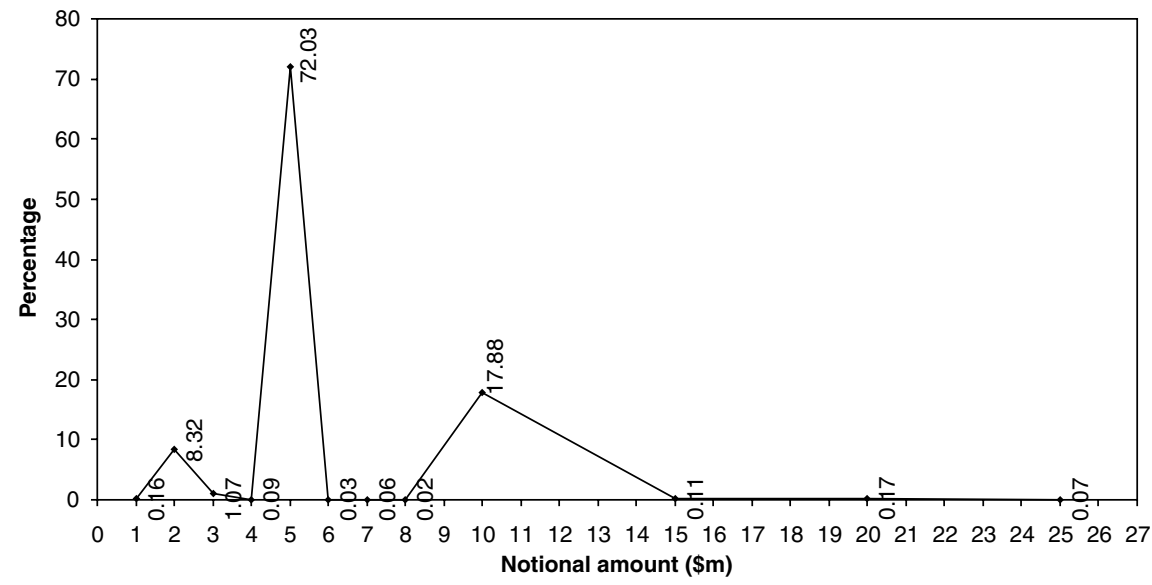

Figure 1: Distribution of notional amount 


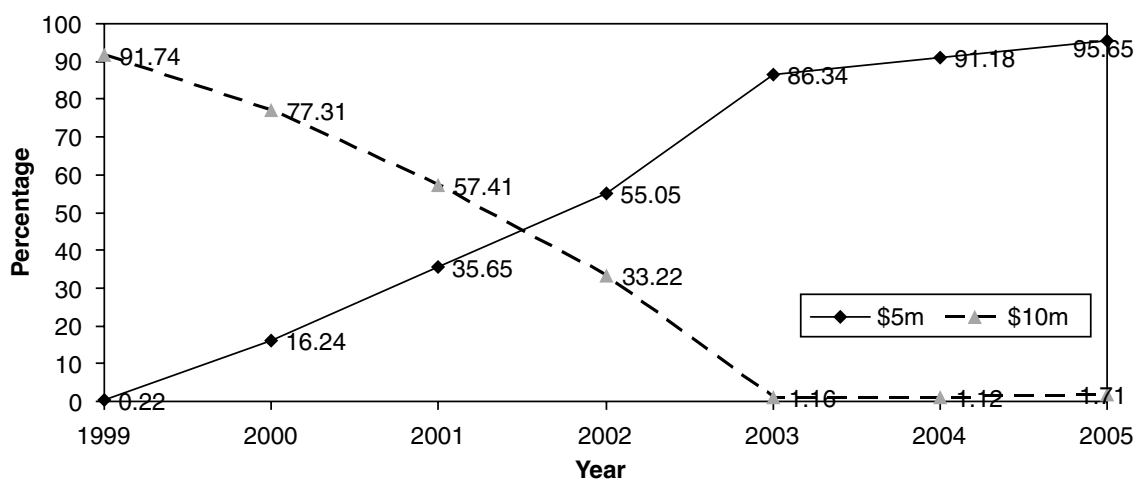

Figure 2: Percentage of the use of $\$ 10$ million and $\$ 5$ million as notional amount * Before 2003, there are CDS observations in the data set without notional amount information, and all the notional amounts in 1997 and 1998 are not available

million, account for more than 95 per cent of all the quotes. Figure 2, however, shows that the $\$ 5$ million notional amount started to dominate the market only since 2002. Before 2002, the use of $\$ 10$ million as notional amount prevailed. This is consistent with Houweling and Vorst's 9 finding that $\$ 10$ million is the most frequently quoted notional amount, given that their sample period is from May 1999 to January 2001.

The increased clustering at $\$ 5$ million amounts may be due to some popular trading strategies in the CDS index market. As investors initially establish a large position in a CDS index and hedge out only a few undesirable reference entities, the notional amounts of single-name CDS they quote may be corresponding to their partial hedging needs and is only a fraction of the initial position in the CDS index. Another potential explanation for this phenomenon is that due to the popularity of $\$ 5$ million as the notional amount, traders may prefer to quote several $\$ 5$ million CDS instead of one quote of the desired notional amount in order to access greater liquidity.

\section{Maturity}

Figure 3 shows the distribution of the most frequently quoted 12 maturities for CDS, which account for around 95 per cent of the whole sample. The frequency is more dispersed than in the case of notional amount. Maturities around five years are the most frequently quoted five maturities, and these account for 83 per cent of the whole sample. 3-year, 2-year, 10-year, 1-year and 7-year maturities are also among the ten most frequently quoted maturities (in descending order). This is similar to Houweling and Vorst's ${ }^{9}$ finding, except that they find that 10-year maturity is the third most common. Hull et al. ${ }^{11}$ and Ericsson et al. ${ }^{10}$ also report that 5 -year maturity CDS represent the majority of the data used in their empirical tests. Figure 4 shows that the use of 5-year maturity and maturities around five years (60-64 months) was increasing until 2002 and levelled off subsequently.

Table 2 shows the time-varying composition of maturities of CDS. In general, the proportion of below 5-year maturities has been declining 


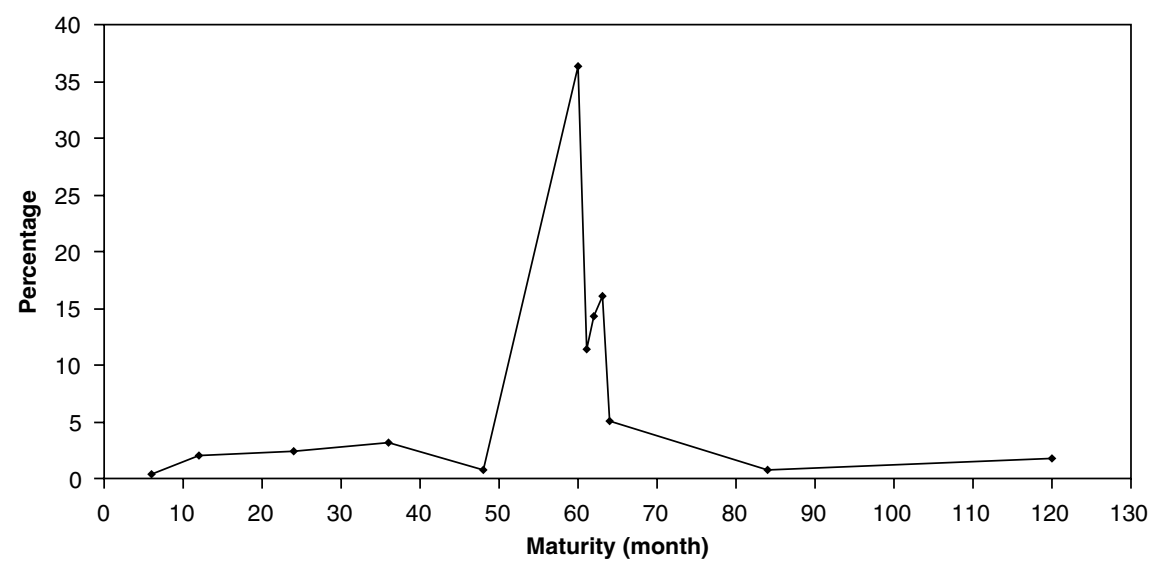

Figure 3: Distribution of maturity

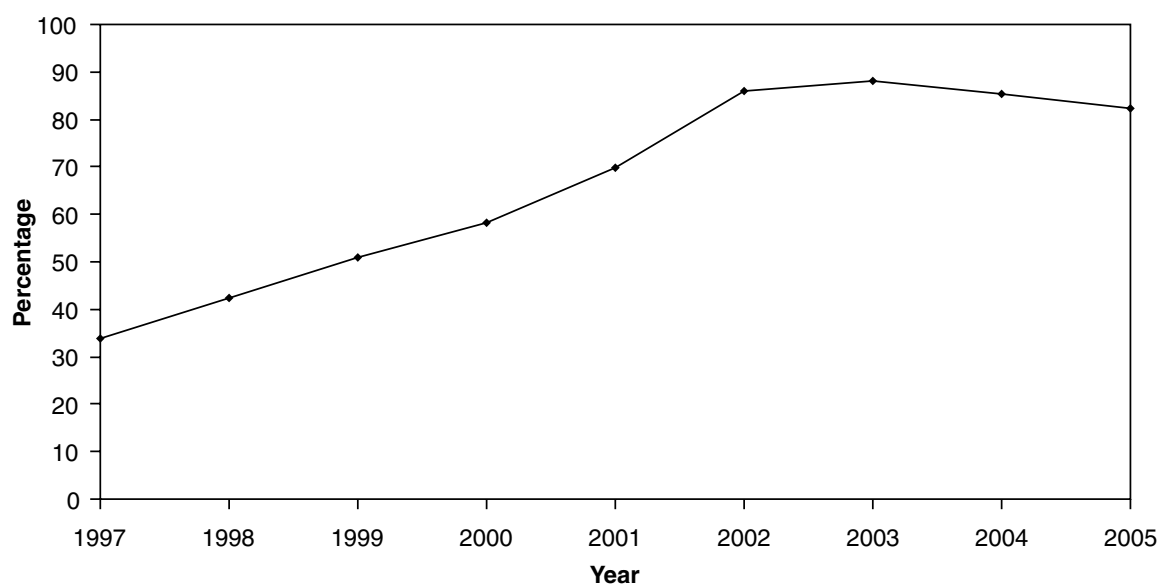

Figure 4: Percentage of the use of 5-year* as maturity

*60-64 month maturities are the most popular maturities in the whole sample and are all included as ' 5 years' in this figure

Table 2: Time-varying composition of maturity

\begin{tabular}{|c|c|c|c|c|c|c|c|c|c|}
\hline \multirow[t]{2}{*}{ Maturity (months) } & \multicolumn{9}{|c|}{ Percentage } \\
\hline & 1997 & 1998 & 1999 & 2000 & 2001 & 2002 & 2003 & 2004 & 2005 \\
\hline$<12$ & 32.346 & 19.539 & 8.383 & 6.783 & 5.763 & 3.294 & 1.731 & 1.590 & 1.175 \\
\hline $13-59$ & 27.654 & 33.020 & 33.614 & 28.031 & 21.010 & 8.891 & 7.624 & 8.724 & 7.494 \\
\hline $60-64$ & 33.827 & 42.491 & 50.954 & 58.111 & 69.880 & 86.030 & 88.261 & 85.325 & 82.379 \\
\hline $65-120$ & 6.173 & 4.949 & 6.709 & 6.940 & 3.264 & 1.713 & 2.227 & 4.225 & 8.577 \\
\hline $121-240$ & 0.000 & 0.000 & 0.340 & 0.135 & 0.084 & 0.072 & 0.145 & 0.132 & 0.375 \\
\hline$>240$ & 0.000 & 0.000 & 0.000 & 0.000 & 0.000 & 0.000 & 0.009 & 0.001 & 0.000 \\
\hline
\end{tabular}


throughout the whole period, while the proportion of the above 10-year maturities has been very low and stable. There has been a modest increase in the proportion of maturities that lie between five and ten years in the last three years.

The phenomenon that maturities of CDS are less clustered than notional amounts of CDS may reflect the fact that breakdown of a target notional amount into $\$ 5$ million units is horizontal. ${ }^{19}$ This can even diversify counterparty risk in CDS transactions if the protection is offered by a number of protection sellers. On the other hand, roll-over of 5-year CDSs to reach a target maturity is vertical and involves 're-investment risk'. If using a 5-year roll-over strategy, the premium that a protection buyer/seller wants to pay/receive may be different at the end of five years. An increase/ decrease in premium will be disadvantageous for the protection buyer/seller.

\section{AVAILABILITY OF CREDIT RATINGS FOR REFERENCE ENTITIES AND CREDIT QUALITY OF THE UNIVERSE}

Unlike previous empirical studies on the determinants of CDS premiums (eg AunonNerin et al. ${ }^{8}$ ) that use credit ratings as an independent variable, analysis of the availability of ratings for reference entities here is to investigate to what extent it is an eligibility criterion for a reference entity to be quoted in the CDS market. The credit rating data for the reference entities are from Financial Times Credit Ratings International.

Among the 945 reference entities, 462 (48.8 per cent) have ratings from FitchRatings, 848 (89.6 per cent) have ratings from Moody's Investors Service and 858 (90.7 per cent) have ratings from Standard \& Poor's Corporation
(S\&P). There are also 293 (30.0 per cent) reference entities that have credit ratings from at least one of six other international rating agencies. These rating agencies are, in descending order of frequency, Dominion Bond Rating Service, Duff \& Phelps, Thomson BankWatch, Canadian Bond Rating Service, ${ }^{20}$ Japan Rating \& Investment Information and Japan Credit Rating Agency (see Panel A of Table 3).

There are 885 (93.6 per cent) reference entities that have ratings from at least one of the three leading rating agencies, and exactly the same number of reference entities have at least one rating. A total of 823 (87.0 per cent) reference entities have ratings from both Moody's and S\&P, 451 (47.7 per cent) have ratings from both FitchRatings and Moody's, 451 (47.7 per cent) have ratings from both FitchRatings and S\&P and 442 (46.7 per cent) have ratings from all the three leading rating agencies (see Panel B of Table 3). There are 549 (58.0 per cent) reference entities that have shortterm ratings.

A total of 624 (66.0 per cent) reference entities are on agencies' rating watch lists at some time during the sample period (see Panel B of Table 3). To compare with the rated universe in general, we identified from Financial Times Credit Ratings International that 39.3 per cent of issuers (excluding the CDS reference entities in our sample) were on a watch list some time during November 1999 to March 2005. The fact that a relatively high proportion of CDS reference entities are on watch lists reflects the ongoing debate surrounding the accuracy of credit ratings versus market-based indicators of credit risk. Changes in CDS premiums, which reflect point-in-time changes in a firm's financial condition, are increasingly used as a 
Table 3: Availability of credit ratings

Panel $A-$ Availability of ratings from different agencies

\begin{tabular}{llllllllll}
\hline Fitch & Moody's & SEP & Others & 1 & 2 & 3 & 4 & 5 & 6 \\
\hline 462 & 848 & 858 & 293 & 59 & 172 & 122 & 14 & 10 & 61 \\
$48.8 \%$ & $89.6 \%$ & $90.7 \%$ & $30.0 \%$ & $6.2 \%$ & $18.2 \%$ & $12.9 \%$ & $1.5 \%$ & $1.1 \%$ & $6.5 \%$
\end{tabular}

Panel $B-$ Additional features

\begin{tabular}{llllllll}
$\begin{array}{l}\text { At least 1 from } \\
\text { main } 3^{\mathrm{a}}\end{array}$ & At least $1^{\mathrm{b}}$ & $\begin{array}{l}\text { Moody's } \\
\text { SEP }\end{array}$ & $\begin{array}{l}\text { Fitch } \\
\text { Moody's }\end{array}$ & $\begin{array}{l}\text { Fitch } \\
\text { SEP }\end{array}$ & $\begin{array}{l}\text { Three } \\
\text { leading }\end{array}$ & Short & Watch \\
\hline 885 & 885 & 823 & 451 & 451 & 442 & 549 & 624 \\
$93.6 \%$ & $93.6 \%$ & $87.0 \%$ & $47.7 \%$ & $47.7 \%$ & $46.7 \%$ & $58.0 \%$ & $66.0 \%$ \\
\hline
\end{tabular}

1=Canadian Bond Rating Service; 2=Dominion Bond Rating Service; 3=Duff \& Phelps; 4=Japan Rating \& Investment Information; 5=Japan Credit Rating Agency; 6=Thomson BankWatch.

${ }^{a}$ Ratings from at least one of the three leading rating agencies.

${ }^{\mathrm{b}} \mathrm{R}$ atings from at least one rating agency.

market-based indicator for credit risk, ${ }^{21}$ that is when there is a market-perceived change in a firm's credit quality, trading of CDS on this firm's outstanding debt becomes more active and CDS premiums also change accordingly. Watch lists, which reflect point-in-time estimates of a firm's credit quality, are issued by rating agencies as a prior warning, to reconcile the dilemma of achieving both accuracy and stability of ratings. Hamilton and Cantor ${ }^{22}$ find that when rating outlooks and watches are taken into consideration, the correlation between credit ratings and CDS premiums is higher. Therefore, it is perhaps not surprising that a majority of CDS reference entities are on agency watch lists.

In our CDS data set, 140 reference entities are quoted in CDS with short maturities, ie less than 12 months. One hundred and five (75 per cent) of these reference entities have short-term ratings during the period. The majority (85.7 per cent) of the 140 reference entities are also on rating watches during the period they are quoted or traded.

Table 4 presents the annual distribution of reference entities that belong to different credit rating bands. The credit rating data used here are from Moody's. The distribution changes substantially across the sample period (except for the lowest band 'Caa1-C'). Reference entities with A1 or above ratings account for a declining proportion since 2000 . The Baa rating band has been the most heavily represented since 2000 . There is a large proportion of $\mathrm{Ba}-$ and $\mathrm{B}$-rated entities at the beginning and the end of the sample period. Each of the rating categories is assigned a number (Aaa as 21 through to $\mathrm{C}$ as 1 ) to calculate the average rating of all the reference entities. Notably, the average rating has been declining since 2002 . The annual average ratings, however, generally float within the 'Baa1-Baa3' rating band. 
Table 4: Time-varying credit quality of the reference entities in our sample

Panel $A-$ Percentage of reference entities within different rating bands

\begin{tabular}{lrrrrrrrrr}
\hline Rating bands & \multicolumn{1}{l}{ Percentage } & \multicolumn{10}{l}{} \\
\cline { 2 - 9 } & 1997 & 1998 & 1999 & 2000 & 2001 & 2002 & 2003 & 2004 & 2005 \\
\hline Aaa-Aa3 & 8.03 & 21.21 & 14.38 & 9.73 & 10.09 & 10.92 & 4.54 & 4.55 & 6.90 \\
A1-A3 & 18.07 & 33.96 & 46.48 & 33.14 & 36.43 & 35.04 & 23.11 & 18.55 & 9.97 \\
Baa1-Baa3 & 11.65 & 19.70 & 21.42 & 34.56 & 38.83 & 42.60 & 61.22 & 46.39 & 37.80 \\
Ba1-Ba3 & 15.26 & 14.27 & 5.25 & 2.12 & 4.07 & 7.59 & 6.16 & 15.17 & 20.70 \\
B1-B3 & 46.99 & 10.86 & 12.47 & 20.45 & 10.17 & 3.83 & 4.54 & 15.29 & 24.54 \\
Caa1-C & 0.00 & 0.00 & 0.00 & 0.00 & 0.41 & 0.02 & 0.43 & 0.06 & 0.08
\end{tabular}

Panel B - Average rating of all reference entities

\begin{tabular}{|c|c|c|c|c|c|c|c|c|c|}
\hline Average & 10.20 & 13.15 & 13.25 & 12.38 & 12.95 & 13.31 & 12.39 & 11.44 & 10.58 \\
\hline
\end{tabular}

${ }^{\mathrm{a}}$ In Panel A, the percentage is calculated based on reference entities that have Moody's ratings available. In Panel $\mathrm{B}$, the calculation of average rating is based on the following recoding: each of Moody's rating categories is assigned a number, with Aaa being 21 and $\mathrm{C}$ being 1.

TRADING ACTIVITY AND CDS INDICES

\section{Quotes and trades, reference entities and trading activity}

Hull et al. ${ }^{11}$ found that the annual number of CDS quotes and trades in their data set increased from 4,759 in 1998 to 125,000 in 2002. Ericsson et al. ${ }^{10}$ demonstrate the trend of the changes in the daily number of CDS quotes and trades graphically. FitchRatings find that the number of unique reference entities increased between January 2002 and September 2004. ${ }^{6}$ On average, the weekly number of quoted reference entities increased from 325 in the first quarter of 2002 to 581 in the third quarter of 2004. The number of reference entities quoted in the market measures, to some extent, the growth of the CDS market. As the use of CDS becomes increasingly popular, additional participants engage in trading and the scope of demand and supply of protection is wider.

Table 5 presents the summary statistics of the number of reference entities in our sample from 10th June, 1997 to 3rd March, 2005. First, the average number of reference entities quoted daily increased steadily from 1997 to 2002, and then stabilised. The maximum daily number of reference entities quoted has been rising throughout the period.

Investigating the ratio of the number of CDS bid prices to that of offer prices reveals a balance at approximately 1:1 since late 1999 (see Figure 5). These results are, however, inconsistent with FitchRatings' finding that there is a structural imbalance in the CDS market, ${ }^{6}$ that is the number of bids to buy protection consistently exceeds the number of 
Table 5: Daily number of reference entities and trading activity

\begin{tabular}{llllllllll}
\hline & 1997 & 1998 & 1999 & 2000 & 2001 & 2002 & 2003 & 2004 & 2005 \\
\hline Mean & 2.83 & 4.52 & 14.50 & 20.69 & 32.96 & 53.59 & 50.73 & 50.19 & 56.42 \\
Standard deviation & 1.76 & 3.10 & 7.56 & 9.14 & 16.52 & 16.18 & 17.97 & 19.57 & 22.67 \\
Minimum & 1 & 1 & 1 & 1 & 1 & 1 & 1 & 1 & 4 \\
Maximum & 10 & 14 & 38 & 57 & 88 & 90 & 102 & 101 & 114 \\
Sum $^{\mathrm{a}}$ & 331 & 963 & 3625 & 5277 & 8340 & 13345 & 12784 & 12297 & 2426 \\
\hline
\end{tabular}

${ }^{\mathrm{a}} \mathrm{Sum}$ is the sum of daily number of reference entities in a year.

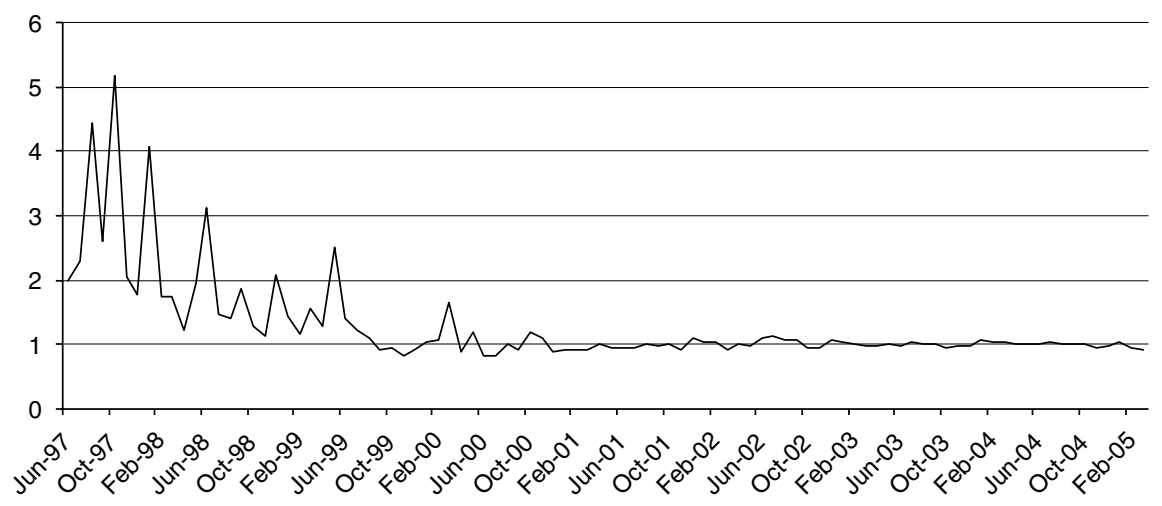

Figure 5: Ratio of number of bids to number of offers (monthly)

offers to sell protection. The probable

explanation for this is the difference in the data samples. The data used in this paper are obtained from CreditTrade covering all the US reference entities quoted from June 1997 to March 2005, while FitchRatings' data are obtained from GFI group and Creditex covering all the reference entities quoted from January 2002 to September $2004 .^{6}$

Figure 6 demonstrates that quotes substantially outnumber trades. Linking to the previous finding that the demand and supply for protection were quite balanced since late 1999, it can be implied that the large number of untraded quotes is not attributable to a bid-offer imbalance. Figure 6 also shows that the quotes/ trades ratio has fallen towards the end of the sample period. One explanation for the falling trend may be that the launch of CDS benchmark indices such as Trac-X series, iBoxx series and iTraxx series helped to improve accuracy in CDS pricing.

\section{Growth of CDS index products and the potential implications for single-name CDS trading}

According to FitchRatings' credit derivatives market surveys, ${ }^{23,24}$ the growth rate of CDS index and index-related products has skyrocketed from 49 per cent in 2003 to 900 per cent in 2005. Meanwhile, the growth rate of 


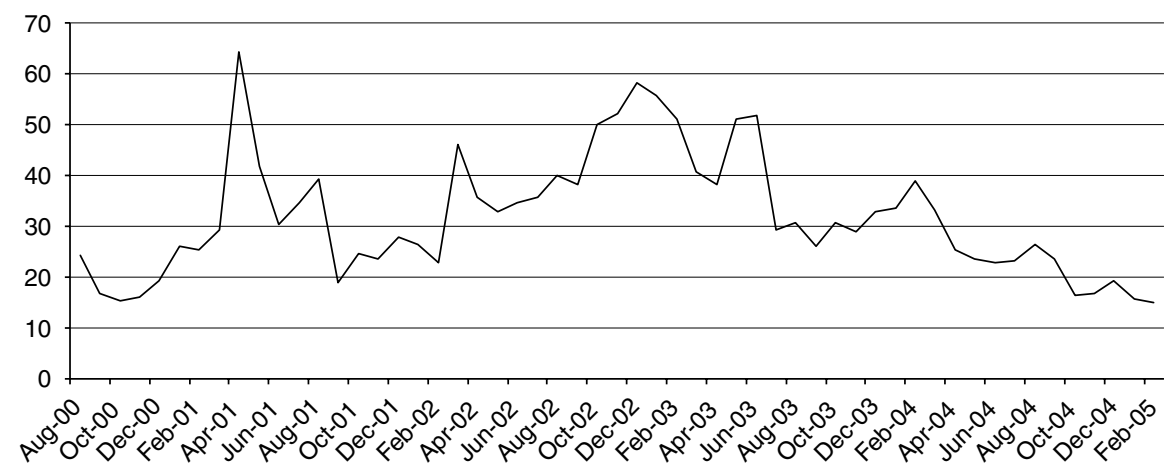

Figure 6: Ratio of monthly quotes to monthly trades

single-name CDS has been declining year by year. The BBA predicted that the share of indexrelated products in the credit derivatives market would rise from 11 to 17 per cent between 2004 and 2006, while the share of single-name CDS would fall from 51 to 42 per cent. ${ }^{25}$

Although there is no hard evidence of a direct causal relationship between the rapid growth of the CDS index market and the slowing of growth of the single-name CDS market, it is well known that CDS indices have some advantages over single-name CDS. Following the merger of Trac-X and iBoxx to iTraxx, the number of market makers has been rising and liquidity has been improving. The introduction of these CDS indices is also a direct product of market participants' demand for pricing benchmarks as the CDS indices consist of highly liquid reference entities. This, according to some practitioners, has created a virtuous circle: investors with surplus cash on a short-term basis are attracted to iTraxx, as the bid-ask spreads are narrow. The participation of these investors brings even more liquidity to the market.

A passive investment strategy of tracking a CDS index, which allows investors to maintain positions in a number of reference entities, is reported to be the most popular strategy with CDS index products. ${ }^{25} \mathrm{~A}$ parallel exists with stock indices that provide opportunities to small investors who lack 'stock-picking' capability. CDS indices attract smaller investors who may not have internal resources to research all the individual reference entities.

\section{The inter-day pattern of volume}

In our database, there are in total 58,828 trades and quotes on Mondays, 84,749 on Tuesdays, 87,365 on Wednesdays, 82,614 on Thursdays and 62,680 on Fridays. The total number of quotes and trades thus demonstrates an inverse U shape throughout weekdays. Previous studies explain such an inter-day pattern of volume in securities markets. On the assumption that private information is received throughout the week while public information is received on weekdays only, Foster and Viswanathan ${ }^{26}$ demonstrate in their model that (i) due to the information advantage (in particular received during weekends), informed traders trade on Mondays even if market makers tend to widen bid-ask spreads to mitigate the information asymmetry problem; (ii) uninformed traders increase their trades after Monday as more public information becomes available; and (iii) liquidity traders avoid trading on Mondays when the bidask spreads are the widest. 
Although there is a lack of previous empirical studies, the information asymmetry problem in the CDS market is widely discussed. ${ }^{27-29}$ Banks who have private information about a reference entity's creditworthiness will exploit this advantage by buying protection before the information goes public. As a result, banks are warned by financial regulators to set up firewalls between their trading and lending desks. ${ }^{30}$ If Foster and Viswanathan's ${ }^{26}$ assumption is valid in the CDS market, their finding can explain why the volume is the lowest on Monday and increases towards Wednesday. The decline in the volume after Wednesday may be due to the fact that liquidity and uninformed traders are not willing to maintain large positions during the weekend due to the unavailability of public information, and therefore they reduce their exposures.

\section{CONCLUSION}

First, the analysis addresses stylised facts of the CDS market. More than 99 per cent of the CDS in our sample are quoted in US dollars. The vast majority of the debt underlying CDS transactions is senior-ranked, a phenomenon that may be attributed to the fact that the pricing for CDS with structured underlying assets is much more complicated. There are few CDS transactions without restructuring clauses and the prevailing restructuring clause with US reference entities is MR. Sovereign CDS cluster on four Latin American countries, namely Brazil, Mexico, Colombia and Venezuela. In a departure from previous findings, we show that the most frequently quoted notional amount is US $\$ 5$ million, which may be attributable to the popular partial hedging practice in CDS index trading. The most popular maturity is around five years. The clustering of maturities, however, is much less than the clustering in notional amounts.

Secondly, we investigate the availability of credit ratings and the credit quality of the reference entities in our sample. The vast majority of the reference entities quoted or traded in the market have ratings from at least one of the three leading rating agencies: Moody's, S\&P and Fitch. The availability of ratings from six other international rating agencies is limited and reference entities are unlikely to have ratings from these rating agencies unless they also have ratings from the three main rating agencies. Each year, there are significant changes in the rating status of reference entities in the sample. The average rating has been declining since 2002 .

Finally, we consider the time-varying characteristics of the data sample. The number of reference entities has grown in the sample period. There is a 'structural imbalance' in this sample of the CDS market up to 2001, whereby bids for protection consistently exceed offers of protection. While the number of quotes substantially exceeds the number of trades, there is a clear change since 2003 , which could be attributed to the launch of a number of CDS benchmark indices. The growth of CDS index trading provides some supportive evidence for the patterns observed in trading activity. In addition, the pattern of volume demonstrates an inverse $U$ shape across the week, with volume increasing from Monday, reaching its peak on Wednesday and then declining afterwards.

\section{Acknowledgments}

The authors acknowledge valuable comments from Haibin Zhu of the Bank for International Settlements, Antonio Di Cesare of Banca d'Italia, and from seminar participants at the Centre for Empirical Finance, University of Wales, Aberystwyth. 


\section{References and Notes}

1 BBA (2002) '2001/2002 Credit Derivatives Survey', British Bankers Association, London.

2 Patel, N. (2003) 'Credit Derivatives Survey: Flow Business Booms', Risk, Vol. 16, pp. 20-23.

3 ISDA (2005) 'Mid-Year Market Survey', International Swaps and Derivatives Association, New York.

4 Longstaff, F., Mithal, S. and Neis, E. (2005) 'Corporate Yield Spreads: Default Risk or Liquidity? New Evidence from the Credit Default Swap Market', Journal of Finance, Vol. 60, pp. 2213-2253.

5 Blanco, R., Brennan, S. and Marsh, I.W. (2005) 'An Empirical Analysis of the Dynamic Relation Between Investment-Grade Bonds and Credit Default Swaps', Journal of Finance, Vol. 60, pp. 2255-2281.

6 FitchRatings (2004) 'CDS Market Liquidity: Show Me the Money', FitchRatings, New York.

7 Another measure of the growth of the market is the outstanding notional amount.

8 Aunon-Nerin, D., Cossin, D., Hricko, T. and Huang, Z. (2002) 'Exploring for the Determinants of Credit Risk in Credit Default Swap Transaction Data: Is Fixed-Income Markets' Information Sufficient to Evaluate Credit Risk?', Working Paper, University of Lausanne.

9 Houweling, P. and Vorst, T. (2003) 'Pricing Default Swaps: Empirical Evidence', Paper presented at Forecasting Financial Markets Conference, Paris.

10 Ericsson, J., Jacobs, K. and Oviedo-Helfenberger, R. (2004) 'The Determinants of Credit Default Swap Premia', Working Paper, McGill University.

11 Hull, J., Predescu, M. and White, A. (2004) 'The Relationship Between Credit Default Swap Spreads, Bond Yields, and Credit Rating Announcements', Working Paper, University of Toronto.

12 CreditTrade, incorporated into the UK, is a leading broker in global credit markets, specialised in CDS and secondary loans. CreditTrade provides CDS transaction services through an internet-based online trading platform or through telephone.

13 Polyn, G. (2002) 'CDS: The quest for neutral pricing data', Risk, Special Report, www.risk.net.

14 The rank information for the remaining 0.2 per cent of the sample is not available.

15 Hull, J. and White, A. (2004) 'Valuation of a CDO and an Nth to Default CDS Without Monte Carlo Simulation', Working Paper, University of Toronto.

16 FitchRatings (2005) 'Synthetic Structured Finance Assets and Associated Valuation Processes: Help or Hindrance?', FitchRatings, New York.

17 FitchRatings (2003) 'Fitch Examines the Effect of 2003 Credit Derivatives Definitions', FitchRatings, New York.
18 Before January 2003, users of CreditTrade's trading platform could enter CDS quotes without specifying the notional amount; therefore, there are a substantial number of CDS price observations without notional amount (appearing in the data as ' 0 '). These quotations without notional amount recorded are excluded from the descriptive statistics presented here.

19 For example, instead of bidding for protection on a notional amount of $\$ 20$ million, the protection buyer can execute four $\$ 5$ million contracts at the same time. Hence, a buyer can lock on a desired price at the time of quoting. Breaking down longer maturities into shorter maturities involves roll-over that bears price risk.

20 FitchRatings was formed by the merger of Fitch IBCA and Duff \& Phelps Credit Rating Co (DCR) in June 2000 and FitchRatings acquired Thomson BankWatch in December 2000. Canadian Bond Rating Services was acquired by S\&P in October 2000.

21 Di Cesare, A. (2005) 'Do Market-Based Indicators Anticipate Rating Agencies? Evidence for International Banks', Working Paper, Bank of Italy.

22 Hamilton, D.T. and Cantor, R. (2005) 'Rating Transitions and Default Conditional on Rating Outlooks Revisited: 1995-2005', Special Comment. Moody's Investors Service.

23 FitchRatings (2004) 'Global Credit Derivatives Survey: Single-Name CDS Fuel Growth', FitchRatings, New York.

24 FitchRatings (2006) 'Global Credit Derivatives Survey: Indices Dominates Growth As Banks' Risk Position Shifts', FitchRatings, New York.

25 Moore, P. (2004) 'The Spread of iTraxx', Credit', Incisive Media, London.

26 Foster, F.D. and Viswanathan, S. (1990) 'A Theory of the Interday Variations in Volume, Variance, and Trading Costs in Securities Markets', The Review of Financial Studies, Vol. 3, pp. 593-624.

27 Fink, R. (2004) 'Default Swap Faults', CFO Magazine, www.cfo.com.

28 Rule, D. (2001) 'The Credit Derivatives Market: Its Development and Possible Implications for Financial Stability', Financial Stability Review, No. 10, pp. 117-140.

29 Skinner, F.S. and Diaz, A. (2003) 'An Empirical Study of Credit Default Swaps', The Journal of Fixed Income, Vol. 13, pp. 28-38.

30 Tett, G. (2005) 'Banks warned on insider trading threat posed by market for credit derivatives', Financial Times, London. 